\title{
An Approach towards Enterprise Interoperability Assessment
}

\author{
Mahsa Razavi ${ }^{1}$ and Fereidoon Shams Aliee ${ }^{2}$ \\ ${ }^{1}$ Islamic Azad University, Central Tehran Branch, Poonak, Tehran, Iran \\ Mahsa_r_deyahoo.com \\ ${ }^{2}$ Shahid Beheshti University, G.C., Tehran, Iran \\ F_shams@sbu.ac.ir
}

\begin{abstract}
Enterprise Architecture (EA) as a discipline with numerous and enterprise-wide models, can support decision making on enterprise-wide issues. In order to provide such support, EA models should be amenable to analysis of various utilities and quality attributes. This paper provides a method towards EA interoperability analysis. This approach is based on Analytical Hierarchy Process (AHP) and considers the situation of the enterprise in giving weight to the different criteria and sub criteria of each utility. It proposes a quantitative method of assessing Interoperability achievement of different scenarios using AHP based on the knowledge and experience of EA experts and domain experts, and helps in deciding between them. The applicability of the proposed approach is demonstrated using a practical case study.
\end{abstract}

Keywords: Enterprise Architecture, Interoperability, Quality attribute, Assessment.

\section{Introduction}

Enterprises are complex, highly integrated systems comprised of processes, organizations, information and supporting technologies, with multifaceted interdependencies and interrelationships across their boundaries. Understanding, engineering, and managing these complex social, technical, and infrastructure dimensions are critical to achieving and sustaining enterprise performance [1]. In order to provide such support, Enterprise Architecture (EA) has been emerged. Taking a holistic approach, EA focuses not only on the technical aspects but also on the various aspects of the enterprise upon which the IT systems operate [2].

As enterprise complexity rises there are many more possibilities to consider in designing an optimal enterprise, and so importance of architecting grows.

Through the emphasis on architecting, we look not just at transition from an 'as is' to the 'to be' state, but also at the underlying decision analysis related to considering the various alternative 'could be' states of the new (or transforming) enterprise.

Moreover, because the risk and impact of EA are pervasive across the enterprise, it is critical to perform an architecture assessment before any decision about choosing a scenario. 
The enterprises of this century are truly systems in themselves and as such the properties and design issues for complex systems also relate to complex enterprises. In this field, one of the new research trends is about the way various properties and behaviors of systems relate to enterprises, and how decisions on 'could be' architecture alternatives may be made based on optimization around a given property.

Considering EA, we generally believe that quality attributes (properties) of an enterprise are primarily achieved through EA (same as software architecture [3]). In other words, most of the design decisions embodied by EA are strongly influenced by the need to achieve quality attributes.

One of the important quality attributes of an enterprise is interoperability.

Interoperability is still a vague concept and has many definitions and connotations to different people in different sectors and domains. Starting from a pure software problem in the middle of 90's, interoperability is taking on a wider meaning to cover the many knowledge spaces, dimensions and layers of single and collaborating enterprises [4].

There exist numerous definitions of interoperability, examples from literature are:

- Ability of two or more systems or components to exchange information and to use the information that has been exchanged [5]

- (computer science) the ability to exchange and use information (usually in a large heterogeneous network made up of several local area networks [6])

- Interoperability may occur between two (or more) entities that are related to one another in one of three ways [7]

- Integrated: where there is a standard format for all constituent systems

- Unified: where there is a common meta-level structure across constituent models, providing a means for establishing semantic equivalence

- Federated: where models must be dynamically accommodated rather than having a predetermined meta-model

- Generally speaking, interoperability is the capability for two (or more) systems to exchange information [5] and to use reciprocally their functionality.

Although much the same, here we focus on the last (most general) definition.

Since a decade, although some efforts have been made to develop enterprise interoperability, especially in Europe [8], [9], [10] where several research projects have been launched under FP5/FP6, there is still not an overall satisfactory solution on interoperability. Research in this area is still fragmented. Most of researches and developments are focused on the technology aspect to solve interoperability problems. Few approaches are developed to evaluate the degree of interoperability.

The aim of this paper is to propose a quantitative assessment method of EA interoperability achievement for different EA scenarios, based on the enterprise's situation.

In this approach, a specialized weight is assigned to each interoperability criteria and sub-criteria according to the areas of focus in the enterprise. This is done by using 
the knowledge of a group of EA experts and a group of domain experts. The proposed approach uses AHP for assessing the level of interoperability of each scenario and helps enterprises compare and decide about different scenarios according to the level of interoperability they provide.

As mentioned above, the method in this paper has the additional benefit that the identification of which architecture to use is based on the situation of the enterprise and also the experience of groups of EA and domain experts. The participants are forced to systematically consider all possible combinations. This ensures a broader decision base. Moreover, it allows discussions to be held focusing on the areas where the participants' experiences differ.

The term "EA scenario" is used to denote an architecture, an architecture proposal, or a solution for an enterprise, which can be on any level of granularity. But of course the architecture scenario candidates to be compared should have the same level of granularity.

The case study provided at the end of this paper is an abbreviated version of a study under development in Ports and Maritime Organization of Iran (PMO). This is done to give a more comprehensive presentation of how the method can be used and to demonstrate the efficacy of our approach.

\subsection{Related Work}

In this part we introduce the related work to this research that consists of 3 groups:

1. Analysis methods and tools for software quality, including the Software Architecture Analysis Method (SAAM) [11], the Architecture Tradeoff Analysis Method (ATAM) [12], Abd-Allah and Gacek [13], Wright [14] and the Chiron-2 Software Architecture Description and Evolution Language (C2SADEL) [15]. None of these methods are applicable in the EA domain [10]. These methods focus on evaluating a single software architecture to find out if and where there may be problems in it, while the method in this paper is more aimed towards finding out which EA scenario candidate, of a set of EA scenario candidates, has the most potential to support the mix of quality attributes for a particular enterprise to build.

2. Software quality attribute measurement methods based on MCDM methods, including [16], [17], [18], [19], [20], [21], [22], [23] and [24].

These methods focus on prioritizing and selecting the most appropriate software architecture candidate that supports the desired quality attributes. In this paper, we extended the idea of these methods in the EA domain.

3. The analysis methods in the EA community including [25], [26], [27], [28], [29], [30], [31] and [32].

The main contributions of our approach which makes it different from the above mentioned approaches of group 3 are as below:

1. In our approach, the criteria and sub-criteria of a quality attribute are given different weights according to the EA layers each of them belong to and also the importance of each EA layer in the enterprise. Above mentioned approaches, use causal effect and probability theory, and 
model causal probabilities between quality attributes and criteria. The problem, however, with causal probabilities is that these are more time consuming to find and define in the EA models (compared to weights).

2. Through our approach, we use the knowledge and experience of two groups of experts in our assessment; EA experts and domain experts. This ensures a broader decision base according to different points of view and allows identification of differences in participants' experiences.

3. All above methods use formal languages such as Influence Diagrams or their extended version to support the analysis of EA, but we have used Analytical Hierarchy Process (AHP) as a multi criteria decision making method, which is the first experience of using this method in the field of EA assessment.

\subsection{Outline of Paper}

The remainder of the paper is outlined as follows:

Section 2 is devoted to the explanation of the proposed interoperability assessment method in a step by step manner. In section 3 , we present a case study where the proposed method is used. Finally in section 4 the paper is concluded and future work are introduced.

\section{The Proposed Interoperability Assessment Method}

The objective of this paper is to help the decision makers of an enterprise to decide about different scenarios according to their level of interoperability achievement.

This method can be used when making any decision about EA issues in the enterprise in each of the phases of Target EA Design, Transition Planning and development and EA maintenance. In other words, this method is usable after gathering complete information about the current EA of the enterprise.

In this approach, we have classified interoperability measures as several criteria and sub-criteria using [4].

The approach uses Analytical Hierarchy Process (AHP) for analysis and prioritization of different elements. Different methods may be applied for prioritization [33]. This includes subjective judgment with or without consensus building and methods such as providing a total sum of points to be divided between the items or aspects you would like to prioritize. Most methods have however weaknesses and it is mostly hard to judge the goodness of the prioritization. AHP addresses some of these problems [34], since it allows for a calculation of a consistency index for the prioritization. This opportunity arises from the fact that AHP is based on all pair-wise comparisons of whatever we would like to prioritize.

To better understand the proposed approach, we first precisely describe AHP and then explain the proposed approach in a step by step manner (Fig. 1).

In this figure the boxes with thick border represent the steps that directly use AHP. 


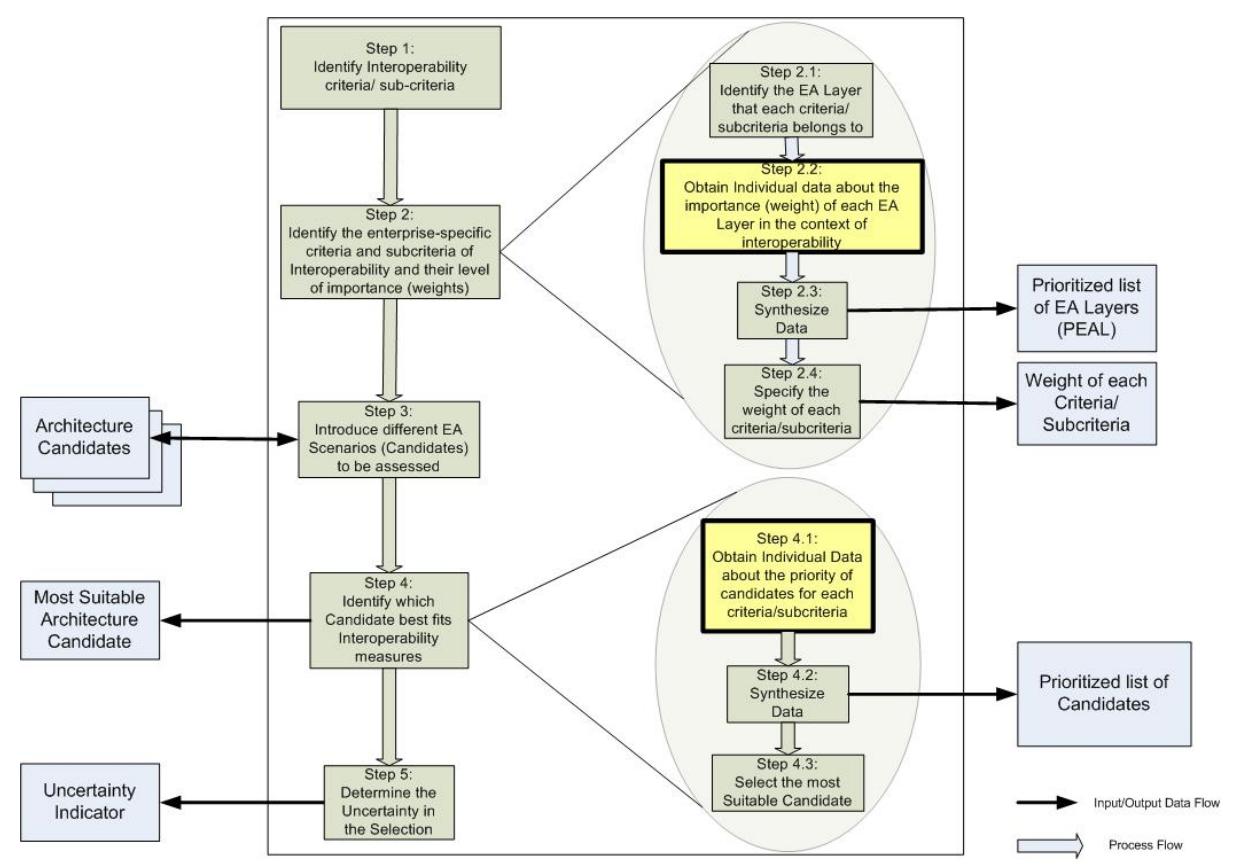

Fig. 1. Illustration of Solution

\subsection{Analytical Hierarchy Process (AHP)}

AHP, originally proposed by Saaty 1980 [34] is one of the multi criteria decision making methods, which is available from the management science literature. Briefly, AHP consists of a set of steps, where all combinations of elements are evaluated pairwise, and according to a certain scale. The question to answer for each pair-wise comparison is which of the two elements, $\mathrm{i}$ or $\mathrm{j}$ is more important, and how much more important is it?. This is rated by interpreting the values as presented in Table 1.

These comparisons are then transferred into a matrix, where $n$ is the number of elements, together with the reciprocal values. After this is done, the eigenvector of the matrix is computed. [34] and [35] propose a method called averaging over normalized columns to do this. This results in an estimation of the eigenvalues of the matrix, and is called the priority vector. The priority vector is the primary output of applying AHP.

After constructing all required pairwise judgment matrices between criteria and alternatives levels, for each, the consistency ratio (CR) should be calculated. The deviation from consistency, the measure of inconsistency, is called the consistency index (CI) and is calculated using the following equation:

$$
C I=\frac{\lambda_{\max }-n}{n-1}
$$

where $\mathrm{n}$ is matrix size and $\lambda_{\max }$ is the maximum eigenvalue of the matrix. 
The CR is used to estimate directly the consistency of pairwise comparisons, and computed by dividing the CI by a value obtained from a table of random consistency index (RI), the average index for randomly generated weights [34], as shown in the following equation:

$$
C R=\frac{C I}{R I}
$$

A consistency ratio of 0.10 or less is considered acceptable even if it is pointed out that higher values are often obtained [34] [35].

Note that if the AHP hierarchy has multiple levels of criteria and sub-criteria, the above computations must be done for each sub-criteria (leaf node of the hierarchy) and then the priority vectors of the alternatives according to each sub-criteria are synthesized into one priority vector [36]. This vector provides the final priorities of the alternatives according to the specified criteria and sub-criteria. A more extensive description of AHP can be found in e.g. [34] and [35].

Table 1. Scale for pairwise comparison using AHP [34][35]

\begin{tabular}{|l|l|l|}
\hline Relative Intensity & \multicolumn{1}{|c|}{ Definition } & \multicolumn{1}{c|}{ Explanation } \\
\hline 1 & Of equal importance & $\begin{array}{l}\text { The two variables (i and } \mathrm{j} \text { ) are } \\
\text { of equal importance }\end{array}$ \\
\hline 3 & $\begin{array}{l}\text { Slightly more } \\
\text { important }\end{array}$ & $\begin{array}{l}\text { One variable is slightly more } \\
\text { important than the other }\end{array}$ \\
\hline 5 & Highly more important & $\begin{array}{l}\text { One variable is highly more } \\
\text { important than the other }\end{array}$ \\
\hline 7 & $\begin{array}{l}\text { Very highly more } \\
\text { important }\end{array}$ & $\begin{array}{l}\text { One variable is very highly } \\
\text { more important than the other }\end{array}$ \\
\hline $2,4,6,8$ & $\begin{array}{l}\text { Extremely more } \\
\text { important }\end{array}$ & $\begin{array}{l}\text { One variable is extremely more } \\
\text { important than the other }\end{array}$ \\
\hline Reciprocal & Immediate values & $\begin{array}{l}\text { Used when compromising } \\
\text { between the other numbers }\end{array}$ \\
\hline & $\begin{array}{l}\text { If variable i has one of the above numbers assigned to it } \\
\text { when compared with variable } \mathrm{j}, \text { then variable } \mathrm{j} \text { has the } \\
\text { value } 1 / \text { number assigned to it when compared with } \\
\text { variable I. More formally if } \mathrm{n}_{\mathrm{ij}}=\mathrm{x} \text { then } \mathrm{n}_{\mathrm{ji}}=1 / \mathrm{x}\end{array}$ \\
\hline
\end{tabular}

\subsection{Steps of the Proposed Approach}

In the proposed framework, AHP is used in steps 2.2 and 4.1. It must be regarded that in each of these steps, after AHP computation (according to section 2.1), the consistency ratio (CR) of the pairwise comparisons should be computed to determine the reliability of the results. Whenever CR is more than $10 \%$, pairwise comparison should be done again with more precise information or by other participants with more experience.

\section{Step 1: Identify interoperability criteria/sub-criteria}

As mentioned before, in this paper we have used enterprise interoperability measures mentioned in [4] as EA interoperability criteria and sub-criteria. The hierarchy of interoperability criteria/sub-criteria is demonstrated in Fig. 2. 


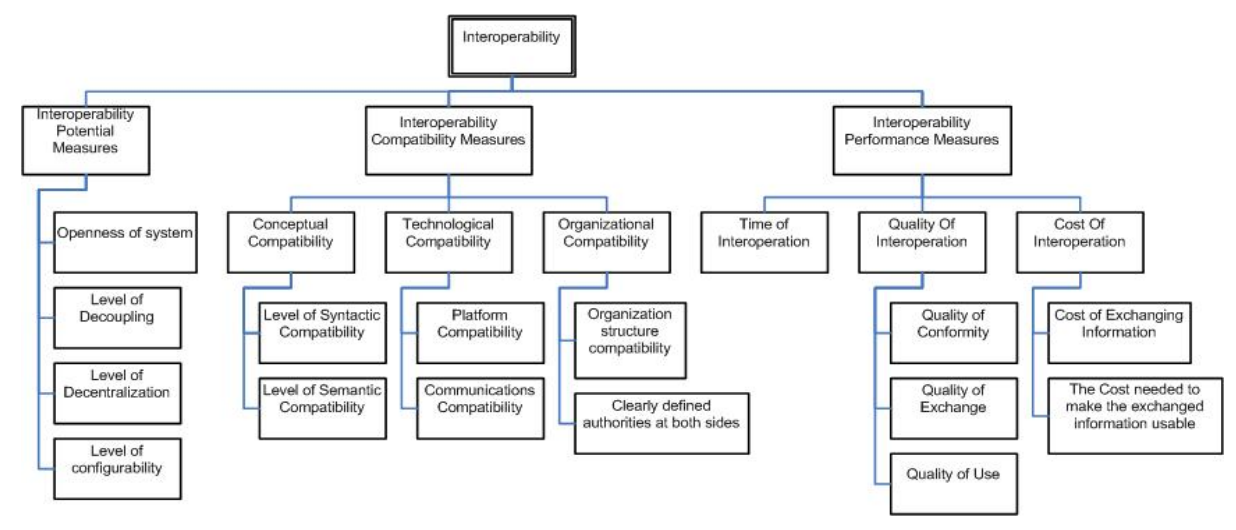

Fig. 2. Interoperability Criteria/sub-criteria hierarchy

Step 2: Identify the enterprise-specific criteria and sub-criteria of interoperability and their level of importance (weight);

The defined criteria are general for enterprises. In this step, an approach is proposed to specify the weight of interoperability criteria and sub-criteria according to the areas of focus in the enterprise. According to [37] and [38], four main aspects (sub architectures or layers) has been specified for EA, which are Business Architecture layer (BAL), Data Architecture layer (DAL), Software Architecture layer (SAL) and Technology Architecture layer (TAL). There are other classifications such as [39] that define 6 aspects for EA, but here we focus on the first classification.

Step 2.1: Identify the EA layer each criteria/sub-criteria belongs to;

As described before, we have specified four main aspects (sub architectures layers) for EA based on [37] and [38], which are Business Architecture layer, Data Architecture layer, Software Architecture layer and technology Architecture layer. In this step an EA expert should specify the EA layer(s) that each criteria/sub-criteria belongs to. One criteria/sub-criteria can belong to more than one EA layer. We have performed this mapping. Table 2 presents the relationship between interoperability criteria/sub-criteria and EA layers.

Step 2.2: Obtain Individual data about the importance (weight) of each EA Layer in the context of the utility;

Regarding the fact that the analysis method used in this paper is AHP, weight of EA layers should be assigned by pair-wise comparison. So, a questionnaire is designed which contains a description of interoperability in each EA layer. For this purpose, the most important and tangible criteria of interoperability for each EA layer are described. Then some of the main experts of the enterprise are asked to fill the questionnaire and do pair-wise comparison between the EA layers. They should give a number between 1 and 9 to each comparison between two layers. This number represents the opinion of the expert about the importance of the considered layer compared to the other layer in the context of interoperability in the enterprise. The outcome of this step using AHP, is one vector per participant with relative weights on the importance of each EA layer in the enterprise. 
Table 2. Interoperability Criteria/sub-criteria and their related EA Layers

\begin{tabular}{|l|c|}
\hline Criteria/Sub-criteria & Related EA Layers \\
\hline Openness of system & All layers \\
\hline Level of Decoupling & BAL, SAL \\
\hline Level of Decentralization & BAL, SAL \\
\hline Level of Configurability & SAL \\
\hline Level of Syntactic Compatibility & DAL, SAL \\
\hline Level of Semantic Compatibility & BAL, DAL, SAL \\
\hline Platform Compatibility & TAL \\
\hline Communications Compatibility & TAL \\
\hline Organization Structure Compatibility & BAL \\
\hline Clearly defined authorities at both sides & BAL \\
\hline Time of Interoperation & BAL, SAL \\
\hline Quality of Conformity & All layers \\
\hline Quality of Exchange & All layers \\
\hline Quality of Use & All layers \\
\hline Cost of Exchanging information & All layers \\
\hline $\begin{array}{l}\text { The Cost needed to make the exchanged information } \\
\text { usable }\end{array}$ & All layers \\
\hline
\end{tabular}

\section{Step 2.3: Synthesize data;}

The median value of the individual vectors produced in the previous step, is then used to create a single vector, called PEAL (Prioritized list of EA Layers). This vector represents the weight of each EA layer in the context of interoperability in the enterprise.

\section{Step 2.4: Specify the weight of each criteria/sub-criteria;}

The weight of each criteria/sub-criteria of interoperability is equal to the weight of the EA layer it belongs to and:

- If a criteria/sub-criteria belongs to more than one EA layer, then its weight will be the maximum weight of the EA layers.

- If the weight of a criteria/sub-criteria is zero, then the criteria/sub-criteria and all its sub-criteria should be omitted

In this approach, the reason of indirectly giving weights to criteria/sub-criteria using the EA layers, instead of directly doing so by the experts, is related to the knowledge of the enterprises' experts. The enterprises' experts might not have enough knowledge about all the criteria/sub-criteria of a quality attribute and by using a more abstract grouping it becomes easier for them to prioritize the criteria/sub-criteria of the quality attribute.

\section{Step 3: Introduce different EA scenarios (candidates) to be assessed;}

In this step, different EA scenarios to be assessed should be described completely so that participants understand the differences and similarities between them. 


\section{Step 4: Identify which candidate best fits interoperability measures;}

In this step, different EA scenarios are assessed and prioritized using AHP. Through this step, we use the opinion of different EA experts for selecting the best candidate scenario.

\section{Step 4.1: Obtain individual data about the priority of candidates for each criteria/sub-criteria;}

In this sub-step, for each of the leaf nodes in the criteria/sub-criteria hierarchy, EA candidate scenarios are compared with each other using pair-wise comparison process.

As a result of applying AHP, each candidate scenario is assigned a normalized value which represents its priority within all candidate scenarios. The outcome of the prioritization process is one vector per participant with relative weights on the compliance of the EA scenarios with interoperability in the enterprise. We call each resultant vector individual Prioritized list of Candidates (iPC).

\section{Step 4.2: Synthesize data;}

The individual vectors created in the previous section are then synthesized into a combined view of all of the participants. We have found that the easiest way to do this is by taking the median values of all of the participants. This resultant vector is called Prioritized list of Candidates (PC).

\section{Step 5: Determine the uncertainty in the selection;}

In order to obtain the uncertainty in our selection we need to calculate the variance for each EA scenario candidate $i$. Since each value in PCQA vector set is the average of $\mathrm{k}$ values (each vector set includes the data obtained from each participant and k represents the number of participants), we can calculate the variance of these sets of data in the ordinary way.

The uncertainty in our selection is equal to the variance of PCQA vector sets:

$$
\text { Uncertainty for EA scenario candidate } \mathrm{i}=\mathbf{1} / \mathbf{k}\left(\sum_{\mathrm{i}, \mathrm{j}}\left(\mathbf{i P C}_{\mathbf{i}, \mathrm{j}} \mathbf{P} \mathbf{P C}_{\mathbf{i}, \mathrm{j}}\right)^{\mathbf{2}}\right.
$$

If there is high uncertainty, this may indicate that the architecture candidates and the quality attribute are not so well understood by the participants, and that further investigations are necessary before the final architecture decision is taken.

\section{A Case Study Using the Method}

In order to illustrate the method described in this paper, we present a summary of an experiment conducted using the method. This is done to give a more comprehensive presentation of how the method can be used.

Our case study is conducted in Ports \& Maritime Organization of Iran (PMO).

This enterprise as the maritime administration of Iran administers the ports and commercial maritime affairs of the country.

Below, we describe how each step of the method is applied in the study. Because of lack of space, the application of the approach in PMO is described precisely. Note that in the proposed approach for interoperability, step 1 and 2.1 are always the same. 


\section{Step 1: Identify interoperability criteria/sub-criteria;}

As described in section 2.2, Fig. 2 illustrates the criteria/sub-criteria hierarchy of interoperability

Step 2: Identify the enterprise-specific criteria and sub-criteria of quality attributes and their level of importance (weight);

Step 2.1: Identify the EA layer that each criteria/sub-criteria belongs to;

As described before, Table 2 presents the mapping between interoperability criteria/sub-criteria and EA layers.

Step 2.2: Obtain Individual data about the importance (weight) of each EA Layer in the context of the utility;

For this purpose, a questionnaire was designed in which it described interoperability by using the most important and tangible criteria in each EA layer. Then ten domain experts of the enterprise were asked to fill the questionnaire and do pair-wise comparison between the EA layers. At the end of this step, we gathered 10 vectors, as the result of using AHP method, each containing relative weights on the importance of each EA layer in the enterprise.

Step 2.3: Synthesize data;

Table 3 illustrates PEAL, which is the median value of the individual vectors produced in the previous step.

Table 3. The importance of EA layers as a result of using AHP

\begin{tabular}{|l|c|}
\hline Architecture Layer & Weight \\
\hline Business Architecture Layer & 0.2 \\
\hline Data Architecture Layer & 0.3 \\
\hline Software Architecture Layer & 0.2 \\
\hline Technology Architecture Layer & 0.3 \\
\hline
\end{tabular}

Step 2.4: Specify the weight of each criteria/sub-criteria;

Table 4 represents the weight of each criteria/sub-criteria of interoperability.

\section{Step 3: Introduce different EA scenarios (candidates) to be assessed;}

One of the functionalities of PMO is to interoperate with some Maritime Shipping Agencies. These agencies give different maritime and shipping services. PMO issues different certificates for qualified agencies and allows them to provide related services. Also PMO supervises their services and their quality of work. Regarding the fact that interoperability between PMO and these agencies is important for PMO, one criteria for prioritizing these agencies, is their ability to interoperate efficiently with PMO. There are times when PMO wants to prioritize maritime shipping agencies according to their interoperability levels.

Here we consider two maritime shipping agencies and the following step presents the process of prioritizing them. 
Table 4. Weight of each criteria/sub-criteria of interoperability in PMO

\begin{tabular}{|l|c|}
\hline Criteria/Sub-criteria & Weight \\
\hline Openness of system & 0.3 \\
\hline Level of Decoupling & 0.2 \\
\hline Level of Decentralization & 0.2 \\
\hline Level of Configurability & 0.2 \\
\hline Level of Syntactic Compatibility & 0.3 \\
\hline Level of Semantic Compatibility & 0.3 \\
\hline Platform Compatibility & 0.3 \\
\hline Communications Compatibility & 0.3 \\
\hline Organization Structure Compatibility & 0.2 \\
\hline Clearly defined authorities at both sides & 0.2 \\
\hline Time of Interoperation & 0.2 \\
\hline Quality of Conformity & 0.3 \\
\hline Quality of Exchange & 0.3 \\
\hline Quality of Use & 0.3 \\
\hline Cost of Exchanging information & 0.3 \\
\hline The Cost needed to make the exchanged information usable & 0.3 \\
\hline
\end{tabular}

\section{Step 4: Identify which candidate best fits the interoperability measures;}

In this step, to assess and prioritize the EA scenarios, we used the opinion of five EA experts.

Step 4.1: Obtain individual data about the priority of candidates for each criteria/sub-criteria;

The EA experts were asked to compare the EA scenarios based on each of the leaf nodes in the criteria/sub-criteria hierarchy.

The outcome of the prioritization process is one vector per participant with relative weights on the compliance of the EA scenarios with EA interoperability in the enterprise.

Step 4.2: Synthesize data;

Table 5 illustrates prioritized list of candidates of PMO for EA interoperability.

Table 5. Prioritized list of EA scenarios

\begin{tabular}{|l|c|}
\hline EA Scenario & Weight \\
\hline EA Scenario1 & 0.4 \\
\hline EA Scenario2 & 0.6 \\
\hline Sum & 1 \\
\cline { 2 - 2 }
\end{tabular}

\section{Step 5: Determine the uncertainty in the selection;}

Here we had only two scenarios to choose from, so the VAR vector has identical elements as shown in Table 6: 
Table 6. The variance of Prioritized list of EA scenarios

\begin{tabular}{|l|c|}
\hline EA Scenario & Variance \\
\hline EA Scenario1 & 0.010776 \\
\hline EA Scenario2 & 0.010776 \\
\hline
\end{tabular}

So the uncertainty of our selection is equal to 0.01 which represents that the results are acceptable.

\section{Conclusion and Future Work}

In this paper we present a quantitative assessment method of EA quality attribute achievement for different EA scenarios and use it for interoperability. This method can be applied to indicate the architecture candidates that best suit the interoperability criteria defined by the enterprise. It also can be used to hold focused discussions on areas where there are disagreements, between participants of the assessment, to increase the confidence that the correct decision is taken.

This paper is a customization of the idea of [40] in the field of interoperability.

The major benefits of the method are listed as below:

- It considers enterprises' situation in specifying and giving weight to different criteria/sub-criteria of the quality attributes

- It considers all possible combinations in assessing a quality attribute

- It calculates consistency ratio of each AHP prioritization and also uncertainty of the final selection. If these values are out of specified range, the corresponding process should be redone with more precise information or by other participants with more experience.

- It uses the experience and knowledge of EA experts and domain experts and clearly indicates disagreements between participants.

As future work we can consider case studies covering other quality attributes besides interoperability and illustrate the tradeoff between them supported by the approach. As another future work, we can introduce the use of Analytical Network Process (ANP) as another MCDM method in EA Analysis. This method considers the interdependencies between hierarchy nodes and creates a network of nodes. This contradicts with AHP that considers each node independently.

\section{References}

1. Nightingale, D.J., Rhodes, D.H.: Enterprise Systems Architecting: Emerging Art and Science within Engineering Systems. In: MIT Engineering Systems Symposium (2004)

2. Armour, F.J., Kaisler, S.H., Liu, S.Y.: Building an enterprise architecture step by step. IEEE IT Professional 1(4), 31-39 (1999)

3. Bass, L., Klein, M., Bachmann, F.: Quality Attribute Design Primitives and the Attribute Driven Design Method. In: 4th International Workshop on Product Family Engineering (2001) 
4. Chen, D., Vallespir, B., Daclin, N.: An Approach for Enterprise Interoperability Measurement. In: Proceedings of MoDISE-EUS (2008)

5. IEEE, IEEE (Institute of Electrical and Electronics Engineers): Standard Computer Dictionary- A Compilation of IEEE Standard Computer Glossaries (1990)

6. WordNet Browser 2.1, Princeton University Cognitive Science Lab

7. ISO 14258, Concepts and Rules for Enterprise Models TC 184/SC5/WG1 (1998)

8. ATHENA Integrated Project, Guidelines and Best Practices for Applying the ATHENA Interoperability Framework to Support SME Participation in Digital Ecosystems, Deliverable DA8.2 (2007)

9. EIF, European Interoperability Framework for PAN-European EGovernment services, IDA working document - Version 4.2 (2004)

10. INTEROP, Enterprise Interoperability-Framework and knowledge corpus - Final report, INTEROP NoE, FP6 - Contract $n^{\circ}$ 508011, Deliverable DI.3 (May 21, 2007)

11. Kazman, R., Abowd, G., Bass, L., Clements, P.: Scenario-Based Analysis of Software Architecture. IEEE Software, 47-55 (1996)

12. Clements, P., Kazman, R., Klein, M.: Evaluating Software Architectures: Methods and Case Studies. Addison-Wesley, Reading (2001)

13. Gacek, C.: Detecting Architectural Mismatch During System Composition. PhD. Thesis, University of Southern California (1998)

14. Allen, R., Douence, R., Garlan, D.: Specifying and Analyzing Dynamic Software Architectures. In: Proceedings of the 1998 Conference on Fundamental Approaches to Software Engineering (1998)

15. Medvidovic, N., Rosenblum, D., Taylor, R.: A Language and Environment for Architecture-Based Software Development and Evolution. In: Proceedings of the 21st International Conference on Software Engineering (1999)

16. Svahnberg, M., Wohlin, C., Lundberg, L., Mattsson, M.: A quality-driven decision-support method for identifying software architecture candidates. International Journal of Software Engineering and Knowledge Engineering 13(5), 547-573 (2003)

17. Al-Naeem, T., Gorton, I., Babar, M.A., Rabhi, F., Benatallah, B.: A quality-driven systematic approach for architecting distributed software applications. In: Proceedings of the 27th International Conference on Software Engineering (ICSE), St. Louis, USA, pp. 244-253 (2005)

18. Svahnberg, M., Wohlin, C., Lundberg, L., Mattsson, M.: A method for understanding quality attributes in software architecture structures. In: Proceedings of the 14th international conference on Software engineering and knowledge engineering (SEKE), pp. 819-826 (2002)

19. Davidsson, P., Johansson, S., Svahnberg, M.: Using the Analytic Hierarchy Process for Evaluating Multi-Agent System Architecture Candidates. In: 6th International Workshop on Agent-Oriented Software Engineering (AOSE), pp. 205-217 (2005)

20. Buyukozkan, G., Ruan, D.: Evaluation of software development projects using a fuzzy multi-criteria decision approach. Mathematics and Computers in Simulation 77(5-6), 464475 (2008)

21. Mikhailov, L., Tsvetinov, P.: Evaluation of services using a fuzzy analytic hierarchy process. Appl. Soft Comput. 5, 23-33 (2004)

22. Lee, K., Choi, H., Lee, D., Kang, S.: Quantitative Measurement of Quality Attribute Preferences Using Conjoint Analysis. In: Gilroy, S.W., Harrison, M.D. (eds.) DSV-IS 2005. LNCS, vol. 3941, pp. 213-224. Springer, Heidelberg (2006) 
23. Zhu, L., Aurum, A., Gorton, I., Jeffery, D.: Tradeoff and Sensitivity Analysis in Software Architecture Evaluation Using Analytic Hierarchy Process. Software Quality Journal 13(4), 357-375 (2005)

24. Reddy, A., Naidu, M., Govindarajulu, P.: An Integrated approach of Analytical Hierarchy Process Model and Goal Model (AHP-GP Model) for Selection of Software Architecture. International journal of Computer Science and Network Security 7(10), 108-117 (2007)

25. Johnson, P., Lagerström, R., Närman, P., Simonsson, M.: Enterprise architecture analysis with extended influence diagrams. Information Systems Frontiers 9(2-3), 163-180 (2007)

26. Närman, P., Johnson, P., Nordström, L.: Enterprise Architecture: A Framework Supporting System Quality Analysis. In: 11th IEEE Enterprise Distributed Object Computing Conference, pp. 130-141 (2007)

27. Johnson, P., Lagerström, R., Närman, P., Simonsson, M.: Extended Influence Diagrams for Enterprise Architecture Analysis. In: 10th IEEE Enterprise Distributed Object Computing Conference, pp. 3-12 (2006)

28. Johnson, P., Lagerström, R., Närman, P., Simonsson, M.: Extended Influence Diagrams for System Quality Analysis. Journal Of Software (JSW) 2(3), 30-42 (2007)

29. Lagerström, R.: Analyzing System Maintainability Using Enterprise Architecture Models. In: Proceedings of the 2nd Workshop on Trends in Enterprise Architecture Research (TEAR 2007), St Gallen, Switzerland, pp. 31-39 (2007)

30. Johnson, P., Johansson, E., Sommestad, T., Ullberg, J.: A Tool for Enterprise Architecture Analysis. In: 11th IEEE Enterprise Distributed Object Computing Conference, pp. 142 156 (2007)

31. Lagerström, R., Johnson, P.: Using Architectural Models to Predict the Maintainability of Enterprise Systems. In: 12th European Conference on Software Maintenance and Reengineering, pp. 248-252 (2008)

32. Ullberg, J., Lagerström, R., Johnson, P.: Johnson P.: Enterprise Architecture: A Service Interoperability Analysis Framework. In: Proceedings of the 4th International Interoperability for Enterprise Software and Applications Conference (I-ESA 2008), pp. 611-623. Springer, Berlin (2008)

33. Karlsson, J., Wohlin, C., Regnell, B.: An Evaluation of Methods for Prioritizing Software Requirements. Information and Software Technology 39(14-15), 938-947 (1998)

34. Saaty, T.L.: The Analytic Hierarchy Process. McGraw Hill, Inc., New York (1980)

35. Saaty, T.L., Vargas, L.G.: Models, Methods, Concepts \&Applications of the Analytic Hierarchy Process. Kluwer Academic Publishers, Dordrecht (2001)

36. Buyukyazici, M., Sucu, M.: The Analytic Hierarchy and Analytic Network Processes. Hacettepe Journal of Mathematics and Statistics 32, 65-73 (2003)

37. Federal Chief Information Officer (CIO) Council: Federal Enterprise Architecture Framework (FEAF). Version 1.1 (1999)

38. Spewak, S.H.: Enterprise Architecture Planning, Developing a Blueprint for Data, Applications and Technology. John Wiley \& Sons, Inc., Chichester (1992)

39. Sowa, J.F., Zachman, J.A.: Extending and Formalizing the Framework for Information Systems Architecture. IBM Journal 31(3), 914-945 (1992) IBM Publication G321-5488. 914-945-3836

40. Razavi, M., Shams Aliee, F.: A New AHP-based Approach towards Enterprise Architecture Quality Attribute Analysis. In: Proceedings of the IEEE International conference on Research Challenges in Information Science, pp. 333-342 (2009) 